\title{
Correlates of N-Terminal Prohormone Brain Natriuretic Peptides in African Americans with Hypertensive Chronic Kidney Disease: The African American Study of Kidney Disease and Hypertension
}

\author{
S. Yia,b G. Contreras ${ }^{d} \quad$ E.R. Miller ${ }^{a-c} \quad$ L.J. Appel ${ }^{a-c} \quad$ B.C. Astor ${ }^{a-c}$ \\ ${ }^{a}$ Welch Center for Prevention, Epidemiology and Clinical Research, Johns Hopkins University, \\ ${ }^{b}$ Department of Epidemiology, Johns Hopkins University, and ' Department of Medicine, Division of General \\ Internal Medicine, Johns Hopkins University School of Medicine, Baltimore, Md., and d Department of Medicine, \\ Division of Nephrology and Hypertension, Miller School of Medicine, University of Miami, Miami, Fla., USA
}

\section{Key Words}

Natriuretic peptides $\cdot$ Epidemiology $\cdot$ Chronic kidney disease

\begin{abstract}
Background/Aims: The N-amino-terminal fragment of the prohormone B-type natriuretic peptide (NT-proBNP) is a marker of cardiac stress and elevated levels are indicative of heart failure. Few correlates of NT-proBNP levels have been identified in persons with moderate chronic kidney disease (CKD), and data from those without heart failure and from African Americans are especially limited. Methods: The African American Study of Kidney Disease and Hypertension (AASK) enrolled nondiabetic African Americans with hypertensive kidney disease (glomerular filtration rate [GFR] $=20$ $65 \mathrm{ml} / \mathrm{min} / 1.73 \mathrm{~m}^{2}$ ) and no evidence of clinical heart failure. NT-proBNP was measured in 982 AASK participants. Results: In unadjusted analyses, GFR $(r=-0.39 ; p<0.001)$, hematocrit $(r=-0.21 ; p<0.001)$ and body mass index (BMl; $r=-0.07$; $p=0.04)$ were inversely correlated, and systolic blood pressure $(r=0.30 ; p<0.001)$ and log UPCR $(r=0.32 ; p<0.001)$ were positively correlated with log NT-proBNP levels. After
\end{abstract}

adjustment for potential confounders, lower GFR and hematocrit and higher systolic blood pressure and protein:creatinine ratio remained significantly associated with higher NTproBNP. Conclusion: Lower GFR and hematocrit, and higher urinary protein excretion may be associated with volume expansion in CKD. These results suggest that these processes are associated with increased NT-proBNP in CKD and may play a role in the development of heart failure.

Copyright $\odot 2008$ S. Karger AG, Basel

\section{Introduction}

Individuals with end-stage renal disease (ESRD) have a significantly elevated risk of cardiovascular disease and heart failure (HF) compared to the general population $[1,2]$. Approximately $40 \%$ of individuals initiating dialysis in the US have a history of diagnosed HF, suggesting that the pathological process leading to clinical HF starts well before the onset of ESRD [3]. Recent data confirm an increased risk of $\mathrm{HF}$ among individuals with moderate kidney dysfunction $[1,4-6]$.

\section{KARGER}

๑) 2008 S. Karger AG, Basel

Fax +4161306 1234 E-Mail karger@karger.ch www.karger.com www.karger.com/ajn
Stella Yi, MPH

Welch Center for Prevention, Epidemiology and Clinical Research

2024 East Monument St, Suite 2-600

Baltimore, MD 21287 (USA)

Tel. +1 410502 3770, Fax +1 410955 0476, E-Mail ssyi@jhsph.edu 
The $\mathrm{N}$-amino-terminal fragment of the prohormone B-type natriuretic peptide (NT-proBNP) is released from cardiac myocytes in response to ventricular wall stretch and tension $[7,8]$. The circulating level of NT-proBNP serves as a sensitive marker of cardiac stress and volume expansion, and elevated levels are indicative of HF [9]. Higher levels of NT-proBNP strongly predict mortality among patients with HF [10] and with acute coronary syndromes [11]. More recently, higher NT-proBNP levels have been shown to predict cardiovascular events and mortality in the general population $[10,12]$.

Chronic kidney disease (CKD) is associated with several abnormalities including anemia, hypertension and proteinuria that place individuals with CKD at higher risk of cardiovascular disease. It is unclear whether these abnormalities explain the increased risk of HF among individuals with CKD. Higher NT-proBNP levels strongly predict $\mathrm{HF}$ and mortality among individuals with $\mathrm{CKD}$, though the correlates of higher NT-proBNP levels have not been fully examined in this population [13]. Several small studies have found a lower glomerular filtration rate (GFR) to be associated with elevated levels of NTproBNP in HF patients [14-16]. An inverse relationship between body mass index (BMI) and NT-proBNP has been observed in patients with HF $[14,17,18]$, but this association has not been studied in the presence of CKD. Few other factors and their relative importance regarding NT-proBNP levels among patients with CKD have been examined, and data from individuals without $\mathrm{HF}$ or from African Americans are especially limited. The current investigation explores correlates of NT-proBNP in a population of African Americans with hypertensive CKD free of clinical HF.

\section{Methods}

The African American Study of Kidney Disease and Hypertension Trial

The African American Study of Kidney Disease and Hypertension (AASK) was a multicenter randomized clinical trial designed to test the effectiveness of three anti-hypertensive drug regimens and two levels of blood pressure control on the progression of hypertensive kidney disease $[19,20]$. The trial enrolled 1,094 self-identified African Americans, aged 18-70 years, with hypertension (diastolic blood pressure of $>95 \mathrm{~mm} \mathrm{Hg}$ ), glomerular filtration rate (GFR) between 20 and $65 \mathrm{ml} / \mathrm{min} / 1.73 \mathrm{~m}^{2}$, urinary protein:creatinine ratio (UPCR) of $<2.5 \mathrm{mg} / \mathrm{g}$ and no other identified causes of renal insufficiency. Exclusion criteria included diabetes (fasting glucose $>140 \mathrm{mg} / \mathrm{dl}$, nonfasting levels of $>200$ $\mathrm{mg} / \mathrm{dl}$ or treatment of diabetes), serious systemic disease and clinical evidence of HF at baseline or the preceding 6 months. Participant enrollment began in February 1995 and ended in Septem- ber 1998. The current investigation is a cross-sectional secondary data analysis of values obtained at the baseline visit of the AASK trial.

Measurement of Demographic, Biochemical and Clinical Data A detailed description of the AASK study protocol has been published [20]. Information collected included a physical exam and history of cardiovascular disease identified by self-report, chart review and 12-lead electrocardiogram (EKG). Seated blood pressure was taken by trained, certified staff using Hawksley random-zero sphygmomanometers. BMI was calculated as weight (in $\mathrm{kg}$ ) divided by height ${ }^{2}$ (in $\mathrm{m}^{2}$ ).

GFR was measured twice prior to randomization by the renal clearance of subcutaneously injected ${ }^{125} \mathrm{I}$-iothalamate, and the mean was used for analysis. A 24-hour urine collection was performed on the day prior to the first pre-randomization GFR measurement. Proteinuria was evaluated based on the ratio of urinary protein to urinary creatinine. Proteinuria was defined as UPCR $>0.22 \mathrm{mg} / \mathrm{g}$ (corresponding to 24-hour urine protein excretion of $\sim 0.3 \mathrm{mg}$ /day). Due to the highly skewed distribution, UPCR was log-transformed for continuous analyses. The difference between total and high-density lipoprotein (HDL) cholesterol was used as an estimate of low-density lipoprotein cholesterol level because low-density lipoprotein cholesterol could not be evaluated in 251 patients at their baseline evaluation.

Levels of NT-proBNP were measured on plasma samples collected at baseline using an electrochemiluminescence sandwich immunoassay (Roche Diagnostics; $\mathrm{CV}=6.0 \%$ ). Study participants were categorized by NT-proBNP levels as undetectable (below the minimally detectable limit of $50 \mathrm{pg} / \mathrm{ml} ; \mathrm{n}=200)$, low $(\geq 50$ $\mathrm{pg} / \mathrm{ml}$ but below the upper reference limits: 88 and $153 \mathrm{pg} / \mathrm{ml}$ in men and women less than 50 years old, respectively; 227 and 334 $\mathrm{pg} / \mathrm{ml}$ in men and women $\geq 50$ years old, respectively; $\mathrm{n}=355$ ), moderate (above the upper reference limits but below the sex-specific median of such values: 472 and $565 \mathrm{pg} / \mathrm{ml}$ in men and women, respectively; $\mathrm{n}=207$ ) or high ( $\geq 472$ and $\geq 562 \mathrm{pg} / \mathrm{ml}$ in men and women, respectively; $\mathrm{n}=208$ ). For the current analysis, participants were excluded if they were missing any of the covariates of interest (e.g. age, NT-proBNP, hematocrit, potassium, years with hypertension, C-reactive protein) resulting in a final sample size of $\mathrm{n}=970$

\section{Statistical Analysis}

Levels of GFR, hematocrit, BMI and other covariates were examined by categories of NT-proBNP and statistical trends were determined using linear or logistic regression, as appropriate. Pearson's correlations between selected covariates and log NTproBNP were also calculated. Crude and adjusted linear and quantile regression models were used to assess the increase of log NT-proBNP that corresponded to a 1 SD change in selected covariates. The adjusted models included age, GFR, hematocrit, BMI, systolic blood pressure (SBP), log UPCR, C-reactive protein, sex, history of heart disease, HDL and non-HDL cholesterol, years with hypertension, and electrocardiographic evidence of left ventricular hypertrophy (LVH; based on Estes criteria). Figures displaying the distribution of selected covariates overlaid with predicted NT-proBNP levels were generated from linear regression models including fourth-order polynomials, adjusted to the population mean levels of all covariates. Analyses were performed using Stata 8.0. (Stata Corp, College Station, Tex., USA). 
Table 1. Descriptive characteristics by NT-proBNP category

\begin{tabular}{|c|c|c|c|c|c|c|}
\hline & \multicolumn{6}{|c|}{ NT-proBNP category* } \\
\hline & overall & undetectable & low & moderate & high & $\mathrm{p}$ trend \\
\hline Number & 970 & 200 & 355 & 207 & 208 & \\
\hline NT-proBNP, median (IQR), pg/ml & $153(63,442)$ & - & $110(77,161)$ & $308(228,413)$ & $1,094(677,2,025)$ & $<0.001$ \\
\hline Glomerular filtration rate, $\mathrm{ml} / \mathrm{min} / 1.73 \mathrm{~m}^{2}$ & $46.5 \pm 13.6$ & $54.2 \pm 11.3$ & $47.8 \pm 12.6$ & $44.4 \pm 14.3$ & $39.0 \pm 12.4$ & $<0.001$ \\
\hline Hematocrit, \% & $39.4 \pm 4.9$ & $41.0 \pm 4.8$ & $39.3 \pm 4.4$ & $39.0 \pm 5.0$ & $38.2 \pm 5.4$ & $<0.001$ \\
\hline BMI & $30.7 \pm 6.6$ & $31.6 \pm 6.3$ & $30.5 \pm 6.3$ & $30.6 \pm 6.9$ & $30.5 \pm 7.1$ & 0.13 \\
\hline Systolic blood pressure, $\mathrm{mm} \mathrm{Hg}$ & $150.2 \pm 24.0$ & $141.3 \pm 20.0$ & $147.7 \pm 23.0$ & $150.6 \pm 23.2$ & $162.8 \pm 24.9$ & $<0.001$ \\
\hline Protein:creatinine ratio, median (IQR) & $0.08(0.03,0.37)$ & $0.03(0.02,0.09)$ & $0.06(0.03,0.23)$ & $0.12(0.04,0.56)$ & $0.24(0.08,0.70)$ & $<0.001$ \\
\hline Proteinuria (Pr:Cr >0.22), n (\%) & $319(33.0)$ & $34(10.7)$ & $92(29.0)$ & $83(26.0)$ & $110(34.6)$ & $<0.001$ \\
\hline C-reactive protein, $\mathrm{mg} / \mathrm{l}$ & $0.8 \pm 1.0$ & $0.7 \pm 0.8$ & $0.8 \pm 1.1$ & $0.8 \pm 1.1$ & $0.8 \pm 1.0$ & 0.27 \\
\hline Age, years & $54.6 \pm 10.6$ & $53.4 \pm 10.6$ & $58.2 \pm 8.8$ & $51.8 \pm 11.0$ & $52.3 \pm 11.3$ & $<0.001$ \\
\hline Female, n (\%) & $378(39.0)$ & $66(17.5)$ & $160(42.3)$ & $75(19.8)$ & $77(20.4)$ & 0.91 \\
\hline History of heart disease, $\mathrm{n}(\%)$ & $504(52.0)$ & $51(13.8)$ & $102(27.5)$ & $93(25.1)$ & $125(33.7)$ & $<0.001$ \\
\hline \multicolumn{7}{|l|}{ Cholesterol, mg/dl } \\
\hline HDL & $48.2 \pm 16.1$ & $45.4 \pm 14.9$ & $49.1 \pm 16.7$ & $48.3 \pm 16.1$ & $49.5 \pm 16.1$ & 0.04 \\
\hline Non-HDL & $163.4 \pm 44.9$ & $176.0 \pm 41.9$ & $163.7 \pm 40.4$ & $158.5 \pm 48.3$ & $156.0 \pm 49.0$ & $<0.001$ \\
\hline Duration of hypertension, years & $14.2 \pm 10.0$ & $12.5 \pm 9.5$ & $15.8 \pm 10.4$ & $13.3 \pm 9.7$ & $14.3 \pm 10.0$ & 0.64 \\
\hline LVH by EKG, n (\%) & $371(38.3)$ & $51(13.6)$ & $102(27.3)$ & $95(25.4)$ & $126(33.7)$ & $<0.001$ \\
\hline \multicolumn{7}{|c|}{$\begin{array}{l}\text { Low }- \text { for }<50 \text { years of age: men: } 50-88 \mathrm{pg} / \mathrm{ml} \text {, women: } 50-153 \mathrm{pg} / \mathrm{ml} \text {; for } \geq 50 \text { years of age: } \mathrm{men}: 50-227 \mathrm{pg} / \mathrm{ml}, \text { women: } 50-334 \mathrm{pg} / \mathrm{ml} \text {. } \\
\text { Moderate }- \text { for }<50 \text { years of age: } \mathrm{men}: 88-472 \mathrm{pg} / \mathrm{ml} \text {, women: } 153-565 \mathrm{pg} / \mathrm{ml} \text {; for } \geq 50 \text { years of age: } \mathrm{men}: 227-472 \mathrm{pg} / \mathrm{ml}, \mathrm{women}: 334-565 \mathrm{pg} / \mathrm{ml} \text {. } \\
\text { High - men: } \geq 472 \mathrm{pg} / \mathrm{ml} \text {, women: } \geq 562 \mathrm{pg} / \mathrm{ml} \text {. }\end{array}$} \\
\hline
\end{tabular}

\section{Results}

Higher NT-proBNP categories were associated with lower mean levels of GFR, hematocrit, age, and non-HDL cholesterol and higher SBP, UPCR, and HDL cholesterol in unadjusted analyses. Participants with higher NTproBNP were more likely to have a history of heart disease and LVH. BMI and C-reactive protein were not associated with NT-proBNP category $(\mathrm{p}=0.13$ and $\mathrm{p}=0.27$, respectively) (table 1 ).

Glomerular filtration rate and hematocrit were inversely correlated with NT-proBNP levels, while SBP and $\log$ UPCR were positively correlated with NT-proBNP levels (table 2). BMI was weakly inversely correlated with NT-proBNP levels $(r=-0.072, p=0.02)$. C-reactive protein was not significantly correlated with NT-proBNP $(\mathrm{r}=0.04, \mathrm{p}=0.21)$.

The difference in log NT-proBNP corresponding to a $1 \mathrm{SD}$ higher level in selected covariates is shown in table 3. The largest difference in log NT-proBNP was observed with a 1 SD higher GFR: each 1 SD $(13.62 \mathrm{ml} /$ $\mathrm{min} / 1.73 \mathrm{~m}^{2}$ ) higher GFR was associated with a $37 \%$ lower mean NT-proBNP level after adjustment. Each 1 SD (4.92\%) higher hematocrit was associated with a $15 \%$ low-
Table 2. Correlations between selected covariates and log NTproBNP levels

\begin{tabular}{lcc}
\hline & Correlation & p value \\
\hline Glomerular filtration rate & -0.39 & $<0.001$ \\
Hematocrit & -0.21 & $<0.001$ \\
BMI & -0.07 & 0.04 \\
Systolic blood pressure & 0.30 & $<0.001$ \\
log protein:creatinine ratio & 0.32 & $<0.001$ \\
C-reactive protein & 0.04 & 0.21 \\
\hline
\end{tabular}

er mean NT-proBNP level. Each $1 \mathrm{SD}\left(6.60 \mathrm{~kg} / \mathrm{m}^{2}\right)$ higher BMI was associated with a $10 \%$ lower NT-proBNP in the unadjusted model, but this association was substantially attenuated after adjustment $(\mathrm{p}=0.34)$. Higher SBP (1 SD = $23.93 \mathrm{~mm} \mathrm{Hg})$ and $\log$ UPCR (1 SD = 1.53) were associated with 30 and 23\% higher mean NT-proBNP levels, respectively. For comparison, a history of CVD was associated with a $48 \%$ higher mean, and LVH was associated with a $27 \%$ higher mean NT-proBNP level after adjustment. No significant difference was observed for Creactive protein before or after adjustment. Similar re- 
Table 3. Crude and adjusted regression coefficients for change in log NT-proBNP corresponding with 1 SD change in covariate

\begin{tabular}{lrll}
\hline & SD & $\begin{array}{l}\text { Crude coefficient } \\
(95 \% \mathrm{CI})\end{array}$ & $\begin{array}{l}\text { Adjusted coefficient } \\
\text { (95\% CI) }\end{array}$ \\
\hline Glomerular filtration rate, $\mathrm{ml} / \mathrm{min} / 1.73 \mathrm{~m}^{2}$ & 13.62 & $-0.55(-0.63,-0.47)$ & $-0.37(-0.46,-0.28)$ \\
Hematocrit, \% & 4.92 & $-0.30(-0.39,-0.21)$ & $-0.15(-0.24,-0.06)$ \\
BMI & 6.60 & $-0.10(-0.19,-0.01)$ & $-0.03(-0.11,0.04)$ \\
Systolic blood pressure, $\mathrm{mm} \mathrm{Hg}$ & 23.93 & $0.43(0.35,0.52)$ & $0.31(0.20,0.42)$ \\
log protein:creatinine ratio & 1.53 & $0.46(0.37,0.54)$ & $0.22(0.13,0.31)$ \\
C-reactive protein, mg/l & 1.02 & $0.06(-0.03,0.15)$ & $0.02(-0.05,0.10)$ \\
\hline
\end{tabular}

\footnotetext{
${ }^{1}$ Adjusted for other covariates listed and age, gender, HDL and non-HDL cholesterol, years with hypertension, and history of heart disease.
}

sults were found for differences in median NT-proBNP levels. The continuous relationships between each predictor and NT-proBNP levels are shown in figures la-e and demonstrate similar results as those observed in the regression analyses. The models fit the data moderately well, ranging from $\mathrm{R}^{2}=0.31$ for systolic blood pressure to $\mathrm{R}^{2}=0.33$ for $\log$ UPCR.

\section{Discussion}

The current analysis found that, in a cohort of African Americans with hypertensive kidney disease and without HF, higher NT-proBNP levels were predicted by lower GFR, lower hematocrit, higher SBP and greater proteinuria. BMI and C-reactive protein were not significantly associated with NT-proBNP levels in our study.

The inverse relationship between GFR and NT-proBNP levels has not been well-characterized among patients without HF. This relationship was independent of the other predictors of NT-proBNP levels and was relatively linear across the range of GFR levels in our study (20-65 ml/min/1.73 $\mathrm{m}^{2}$ ). DeFilippi's group reported results similar to these from a study of 209 ambulatory CKD patients (74\% African American) that included a wider range of both kidney function (stages 1-5) and NT-proBNP levels, suggesting that the results we observed may extend in both directions [7,21]. It is unclear whether the relationship between GFR and NT-proBNP levels is due to impaired renal clearance, or whether kidney function directly or indirectly increases cardiac stress $[8,14]$. Lending credence to the latter hypothesis, a recent analysis in the AASK population found that NTproBNP levels strongly predict cardiovascular disease, including incident events and HF [13]. Thus, reduced clearance by itself is unlikely to be the full explanation for the inverse relationship between kidney function and NT-proBNP.

An inverse association between hematocrit and NTproBNP levels has been reported among patients without HF [22-24]. One potential mechanism may be that a lower hematocrit level leads to increased plasma volume and cardiac output, followed by increased ventricular wall stress [23-25].

We found a weak inverse relationship between BMI and NT-proBNP levels, though no association persisted after adjustment for other factors. Results from previous studies are mixed $[17,26]$. To date, the inverse relationship between obesity and natriuretic peptides remains unresolved. It may be due to increased clearance and decreased synthesis of NT-proBNP among obese individuals, although the former hypothesis has been deemphasized as playing a minor role [27]. In addition, while the relationship between obesity and BNP is well established and has led to recommendations for modification of diagnostic cut-points by BMI, the association between obesity and NT-proBNP is weaker, in part due to the clearance hypothesis, and no difference in diagnostic utility of NT-proBNP by BMI has been demonstrated [27].

Urinary protein excretion was strongly associated with NT-proBNP in our analysis. Proteinuria is a marker of degree of severity of CKD and of endothelial dysfunction, which is related to decreased vascular compliance and increased resistance. In our analysis, the largest difference in NT-proBNP levels occurred at levels below overt proteinuria, between a UPCR of 0.02 to 0.22 , suggesting that a lower cutoff for those with clinically significant proteinuria may be appropriate. 

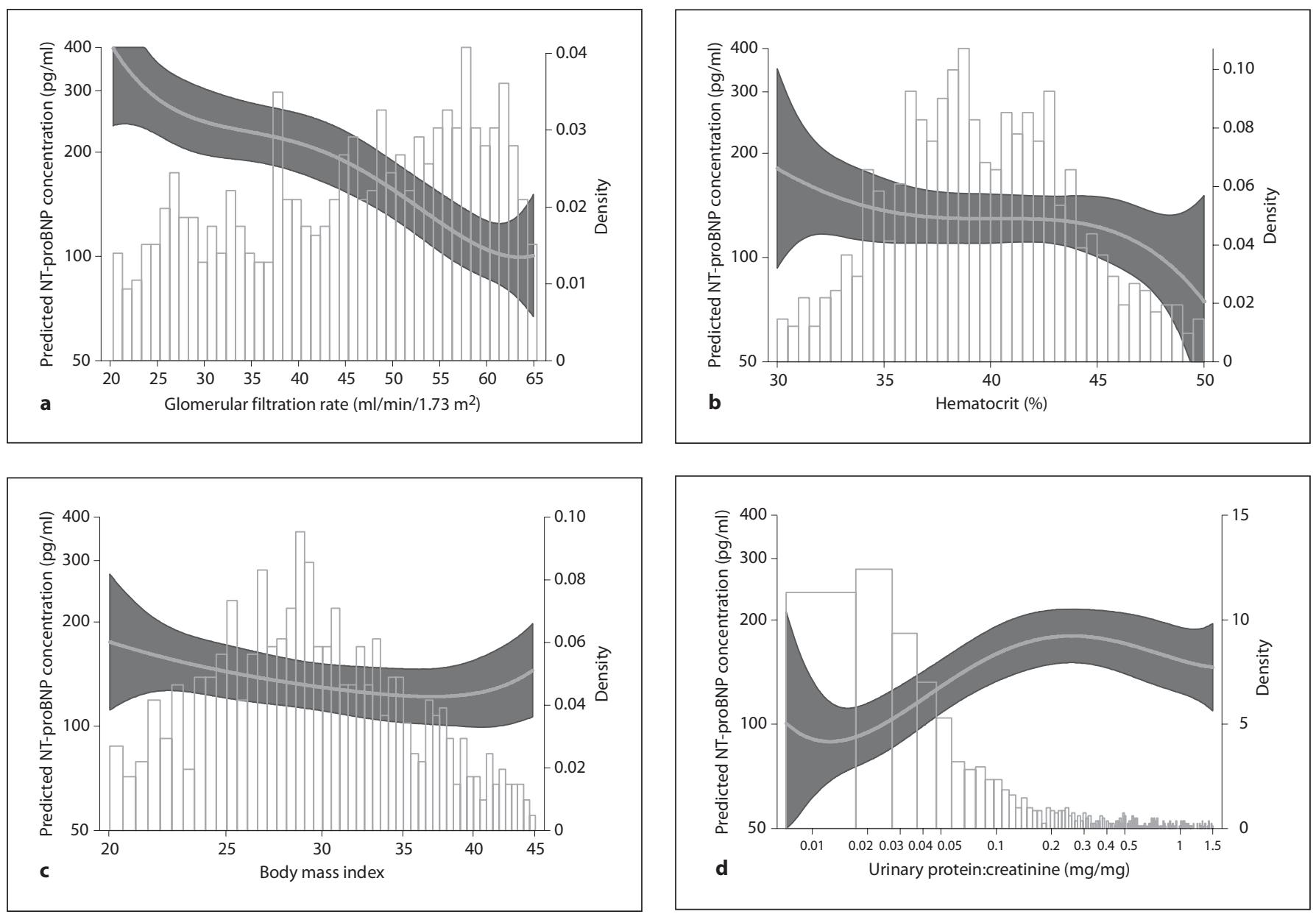

Fig. 1. Predicted NT-proBNP values, by level of (a) glomerular filtration rate $\left(\mathrm{R}^{2}=32.5\right)$, (b) hematocrit $\left(\mathrm{R}^{2}=31.3\right)$, (c) body mass index $\left(\mathrm{R}^{2}=33.0\right)$, (d) urinary protein:creatinine ratio $\left(\mathrm{R}^{2}=33.2\right)$, and $(\mathbf{e})$ systolic blood pressure $\left(\mathrm{R}^{2}=30.8\right)$. Curves were calculated from linear regression models including fourth-order polynomials of the predictor and adjusted for age, sex, diastolic blood pressure, duration of hypertension, presence of left ventricular hypertrophy by EKG, high-density lipoprotein (HDL) cholesterol, nonHDL cholesterol, glomerular filtration rate, hematocrit, log urinary protein:creatinine ratio, systolic blood pressure, and body mass index, as appropriate.

The abnormalities of CKD including lower GFR, anemia, hypertension, and proteinuria, all may reflect the varied pathological processes that lead to HF. Low GFR and anemia, through volume expansion, are associated with increased cardiac pre-load and greater LV diameter

[28]. Hypertension is related to both CKD and HF, and higher SBP increases vascular resistance. Proteinuria serves as a marker of endothelial dysfunction, which in turn is related to vascular changes that may also increase resistance and filling pressure. Levels of NT-proBNP, as 
a marker of cardiac stretch and tension, allow us to detect myocardial changes that may lead to HF. In our analyses, moderately elevated levels of several factors were significantly associated with higher NT-proBNP, underlining their role in the complex processes relating CKD to cardiovascular disease.

An important strength of our analysis is the use of directly measured GFR, in contrast to previous studies that have used estimated values. In addition, most prior studies have investigated NT-proBNP levels in nondiverse populations with heart failure. One limitation is the use of single measurements of predictive factors, such as hematocrit and CRP. In addition, due to the cross-sectional nature of this analysis, we are unable to make statements on the duration of exposure to these risk factors or the temporality of the association observed. We could not evaluate diastolic blood pressure since it was an eligibility criteria for AASK participants (inclusion criteria, resting DBP $<95 \mathrm{~mm} \mathrm{Hg}$ ). Lastly, the generalizability of our results may be limited as our current investigation was conducted in African Americans without diabetes mellitus.

In conclusion, this study identifies several factors associated with NT-proBNP levels in a sample of hypertensive African Americans with CKD and without clinical
HF. Future studies should investigate the association of these factors with incident HF in CKD patients with structural and functional abnormalities, and these factors should be considered in the design and analysis of studies of interventions to preclude incident HF in this high-risk population.

\section{Acknowledgements}

In addition to funding under a cooperative agreement from the National Institute of Diabetes and Digestive and Kidney Diseases (NIDDK), this study was supported in part by the following institutional GCRC and other National Institutes of Health grants: NIH, M01-RR00080, 5M01 RR00071, M01 00032, P20RR11145, M01 RR00827, M01 RR00052, 2p20 R11104, and DK 2818-02. In addition, we gratefully acknowledge support from the Office of Research in Minority Health, the donation of drugs and some financial support to NIDDK by Pfizer, Inc., Asta-Zeneca Pharmaceuticals, and King Pharmaceuticals, Inc. We also gratefully acknowledge the support of Roche Diagnostics, who supplied the materials for the laboratory assay of NT-proBNP.

Abstract submitted, accepted and presented at the American Heart Association Cardiovascular Disease Epidemiology and Prevention Annual Conference, March 13-15, 2008; Colorado Springs, Colo., USA.

\section{References}

1 Sarnak MJ: Cardiovascular complications in chronic kidney disease. Am J Kidney Dis 2003;41:11-17.

2 Foley RN, Parfrey PS, Sarnak MJ: Clinical epidemiology of cardiovascular disease in chronic renal disease. Am J Kidney Dis 1998; 32:S112-S119.

3 USRDS 2005 Annual Data Report: Atlas of End-Stage Renal Disease in the United States. Bethesda, National Institutes of Health, National Institute of Diabetes and Digestive and Kidney Diseases, 2005.

4 Shik J, Parfrey PS: The clinical epidemiology of cardiovascular disease in chronic kidney disease. Curr Opin Nephrol Hypertens 2005; 14:550-557.

5 Sarnak MJ, Levey AS, Schoolwerth AC, et al: Kidney disease as a risk factor for development of cardiovascular disease: a statement from the American Heart Association Councils on Kidney in Cardiovascular Disease, High Blood Pressure Research, Clinical Cardiology, and Epidemiology and Prevention. Hypertension 2003;42:1050-1065.

-6 Kottgen A, Russell SD, Loehr LR, et al: Reduced kidney function as a risk factor for incident heart failure: the atherosclerosis risk in communities (ARIC) study. J Am Soc Nephrol 2007;18:1307-1315.
7 Vickery S, Price CP, John RI, et al: B-type natriuretic peptide (BNP) and amino-terminal proBNP in patients with CKD: relationship to renal function and left ventricular hypertrophy. Am J Kidney Dis 2005;46:610620.

8 Wiese S, Breyer T, Dragu A, et al: Gene expression of brain natriuretic peptide in isolated atrial and ventricular human myocardium: influence of angiotensin II and diastolic fiber length. Circulation 2000;102: 3074-3079.

$\checkmark 9$ Omland T, Aakvaag A, Vik-Mo H: Plasma cardiac natriuretic peptide determination as a screening test for the detection of patients with mild left ventricular impairment. Heart 1996;76:232-237.

10 Kistorp C, Raymond I, Pedersen F, Gustafsson F, Faber J, Hildebrandt P: N-terminal pro-brain natriuretic peptide, C-reactive protein, and urinary albumin levels as predictors of mortality and cardiovascular events in older adults. JAMA 2005;293:16091616
11 Lindahl B, Lindbäck J, Jernberg T, et al: Serial analyses of $\mathrm{N}$-terminal pro-B-type natriuretic peptide in patients with non-ST-segment elevation acute coronary syndromes: a Fragmin and fast Revascularisation during In Stability in Coronary artery disease (FRISC)-II substudy. J Am Coll Cardiol 2005;45:533-541.

12 Wang TJ, Larson MG, Levy D, et al: Plasma natriuretic peptide levels and the risk of cardiovascular events and death. N Engl J Med 2004;350:655-663.

13 Astor BC, Yi S, Hiremath L, Corbin T, Pogue V, Wilkening B, Peterson G, Lewis J, Lash JP, Van Lente F, Gassman J, Wang X, Bakris G, Appel LJ, Contreras G: N-terminal prohormone brain natriuretic peptide (NT-proB$\mathrm{NP}$ ) as a predictor of cardiovascular disease and mortality in African Americans with hypertensive kidney disease: the African American Study of Kidney Disease and Hypertension (AASK). Circulation 2008;117: 1685-1692.

1685-1692.
Schou M, Gustafsson F, Kistorp CN, Corell P, Kjaer A, Hildebrandt PR: Effects of body mass index and age on $\mathrm{N}$-terminal pro brain natriuretic peptide are associated with glomerular filtration rate in chronic heart failure patients. Clin Chem 2007;53:1928-1935. 
15 DeFilippi CR, Seliger SL, Maynard S, Christenson RH: Impact of renal disease on natriuretic peptide testing for diagnosing decompensated heart failure and predicting mortality. Clin Chem 2007;53:1511-1519.

$\checkmark 16$ Hogenhuis J, Voors AA, Jaarsma T, et al: Anaemia and renal dysfunction are independently associated with BNP and NT-proBNP levels in patients with heart failure. Eur J Heart Fail 2007;9:787-794.

-17 Das SR, Drazner MH, Dries DL, et al: Impact of body mass and body composition on circulating levels of natriuretic peptides: results from the Dallas Heart Study. Circulation 2005;112:2163-2168.

18 Krauser DG, Lloyd-Jones DM, Chae CU, et al: Effect of body mass index on natriuretic peptide levels in patients with acute congestive heart failure: a ProBNP Investigation of Dyspnea in the Emergency Department (PRIDE) substudy. Am Heart J 2005;149: 744-750.
19 Gassman JJ, Greene T, Wright JT Jr, et al: Design and statistical aspects of the African American Study of Kidney Disease and Hypertension (AASK). J Am Soc Nephrol 2003; 14:S154-S165.

20 Wright JT Jr, Kusek JW, Toto RD, et al: Design and baseline characteristics of participants in the African American Study of Kidney Disease and Hypertension (AASK) Pilot Study. Control Clin Trials 1996;17:3S$16 \mathrm{~S}$.

21 DeFilippi CR, Fink JC, Nass CM, Chen H, Christenson R: N-terminal pro-B-type natriuretic peptide for predicting coronary disease and left ventricular hypertrophy in asymptomatic CKD not requiring dialysis. Am J Kidney Dis 2005;46:35-44.

22 Willis MS, Lee ES, Grenache DG: Effect of anemia on plasma concentrations of NTproBNP. Clin Chim Acta 2005;358:175181.

23 Knudsen CW, Clopton P, Westheim A, et al Predictors of elevated B-type natriuretic peptide concentrations in dyspneic patients without heart failure: an analysis from the breathing not properly multinational study. Ann Emerg Med 2005;45:573-580.
24 Wu AH, Omland T, Wold Knudsen C, et al: Relationship of B-type natriuretic peptide and anemia in patients with and without heart failure: a substudy from the Breathing Not Properly (BNP) Multinational Study. Am J Hematol 2005;80:174-180.

25 Desai AS, Bibbins-Domingo K, Shlipak MG, Wu AH, Ali S, Whooley MA: Association between anaemia and $\mathrm{N}$-terminal pro-B-type natriuretic peptide (NT-proBNP): findings from the Heart and Soul Study. Eur J Heart Fail 2007;9:886-891.

26 Cortes R, Otero MR, Morillas P, et al: Obese and nonobese patients with essential hypertension show similar N-terminal proBNP plasma levels. Am J Hypertens 2008;21:820825.

27 Bayes-Genis A, DeFilippi C, Januzzi JL Jr: Understanding amino-terminal pro-B-type natriuretic peptide in obesity. Am J Cardiol 2008;101:89-94.

28 Astor BC, Arnett DK, Brown A, Coresh J: Association of kidney function and hemoglobin with left ventricular morphology among African Americans: the Atherosclerosis Risk in Communities (ARIC) study. Am J Kidney Dis 2004;43:836-845. 